\title{
Modern Dance as an American Alternative to Classical Ballet
}

\author{
Tatiana Portnova \\ Department of Art History, Russian State University named after A.N. Kosygin, Moscow, Russian \\ Federation. Email: prof.portnova@nuos.pro
}

\begin{abstract}
The choreographic art of the United States developed in a new direction and was looking for new forms corresponding to the trends of the modern era in many ways. By the beginning of the 20th century, the classical ballet of the USA rooted in Russian choreographic culture had experienced the lack of the means of expression that could reflect a new range of themes, images, philosophical and artistic concepts that had developed by that time and required a new dance style, genres, aesthetics. Modern dance emerged along with the development of the national political and artistic and creative self-consciousness of Americans in general, during the development of national musical, choreographic, and poetic traditions by cultural figures, who searched for their path in art. The study analyses the features of American modern dance. The artistic and aesthetic principles of modern dance are identified and the historical and cultural prerequisites for the development of the national choreographic school of the United States are revealed. The study uses theoretical methods such as visual and textual analysis of choreographic performances and music for performances, comparison of means of plastic expression, movements and figures of classical ballet and modern dance, principles of stage development of artistic images of performances. The empirical study is based on the generalisation of the practical experience of staging performances by leading American dancers of the 20th century. As a result, it is noted that the features of modern dance are completely different to those of the United States classical ballet, testifying to the desire of Americans to reflect the problems of modernity and convey the unique national character of the United States culture by using elements of African or Indian dances, as well as movements that are not characteristic of classical ballet but reflect the spirit of modernity. The materials of the study are of theoretical and practical value for specialists who work with the problems of culture and art of the 20th century, including modern choreography.
\end{abstract}

Keywords: US art, avant-garde, choreography, performance, culture.

\section{Introduction}

Choreographic art in the United States, as well as American society and culture in general, is a relatively young phenomenon. The complex and unique path of development of US culture is the result of the historical, political and social circumstances and the independent research of American thinkers and artists. American state structure, social customs, religious convictions, and art had their specific features. An independent socio-political path, democracy, social justice, freedom and human rights have been and remain the main issues of the American nation. These values predetermined the development of various forms of art, including choreography. The emergence of American culture occurred due to the interaction of not only different national but also racial customs, habits and traditions that developed closely to each other (Anufrieva \& Reale,

This Open Access article is published under a Creative Commons Attribution Non-Commercial 4.0 International License (http://creativecommons.org/licenses/by-nc/4.0/), which permits non-commercial re-use, distribution, and reproduction in any medium, provided the original work is properly cited. For citation use the DOI. For commercial re-use, please contact editor@rupkatha.com. 
1997; Poplavskyi et al., 2020). The United States has combined European, Indian and African traditions. However, the country's originality is developing cutting-edge approaches to these traditions and the non-European vision of the culture in general which includes many ethnic subcultures that have formed a qualitatively new entity in America.

Russian dancers and choreographers played an important role in the development of the national ballet school in the United States, even though at the end of the 18th century, the American dancers J. Durand, O. Maywood, M. Lee, J. Smith, who performed in ballet companies in Europe, gained recognition. At the beginning of the 20th century, A.P. Pavlov and the troupe of S.P. Diaghilev were on tour in America. In the meantime, modern dance has appeared based on the ideas of A. Duncan, which had a great influence on the choreographic art of the United States and determined the path of the development of the national choreographic school. In 1915, R. Saint-Denis and T. Shawn created the first modern dance school and troupe in America. In 1933, L. Kirnstein invited J. Balanchine to organise a ballet school, which pupils entered the first American Ballet troupe in the United States (1934) renamed into New York City Ballet (1948). In 1939, the American Ballet Theatre was established under the leadership of L. Chase and O. Smith, who collaborated with M. Mordkin. The first significant ballet schools in the United States educated a number of famous American dancers and choreographers such as M. Graham, R. Page, A. De Mille, J. Robbins, L. Christensen, H. Lemon, J. Loring, C. Lytfield, D. Humphrey, E. Tamiris, H. Holm, C. Weidman, C. Dunham, M. Cunningham, J. Butler, A. Nicholas, who made a great contribution to the development of US choreographic art and represented two "branches" of the national choreographic art - classical ballet and modern dance (Vedernikova, 2012). Some have staged and performed in classical ballet productions to the music of P.I. Tchaikovsky, I.F. Stravinsky, developing the traditions of Russian classical ballet. Others performed a modern dance based on scenes from American life and the music of contemporary US composers (often of an anti-war and anti-fascist nature).

In their works, the choreographers highlighted the problems of their time and conveyed the unique national character of American culture by using elements from African or Indian dances. In the 1930s, ballet troupes appeared not only in New York but also in Chicago (R. Page and the Christensen brothers), Philadelphia (K. Littlefield), San Francisco and other cities. In the 1950s-1960s, experimental ballet studios appeared in the United States, staging choreographic performances based on modern avant-garde and jazz music, as well as the traditions of the music hall that originated from A. Duncan, R. Saint-Denis and D. Shawn. In the mid-1970s, various types of stage dance developed. For example, there were combinations of choreography with cinema, sculpture and architecture. Classical ballet and modern dance closely interacted and enriched each other. Despite the many styles and trends in American choreographic art, these two types were and remain alternative choreography options of the 20th century, differing in artistic and aesthetic principles, the logic of development of stage imagery, the character and composition of dance movements and figures. Modern dance emerged due to certain historical and socio-cultural circumstances (Mykulina, 2018). It should have appeared since the traditions of classical ballet could not reflect the spirit of the era and the radical avant-garde changes in American art.

During the "Americanisation" of literature, music and painting, dancers and choreographers of the United States found their path for the further development of plastic art, and this path was associated with modern dance. A. Harris (2017) notes in his book "Making Ballet 
American" that "evolution of modernist ballet theory and practice happened during a turbulent historical period. Ultimately, "Making Ballet American" argues that the Americanisation of Balanchine's neoclassicism was not the inevitable outcome of his immigration or his creative genius, but rather a far more complicated process that spanned several authors and continents, always pivoting on the question of modern ballet's relationship to America and the larger world". After modern dance, different choreographic styles appeared in America. One of the most flamboyant among them is musical and choreographic performance as a form of musical theatre in the second half of the 20th century (Kiseyeva, 2017). In the 20th century, one of the main trends in the development of American art is the independent search that was not just following the European samples but was dictated by the real auditory and visual experience of the American artistic and creative environment (Pereverzeva et al., 2018). This explains the growing interest of artists, composers, writers and dancers in the traditional culture of different ethnicities inhabiting America, as well as the appeal to Anglo-Celtic, Indian, African American and Creole folklore. Therefore, the study of the features of American modern dance, which took shape in the first half of the 20th century as an alternative to classical US ballet and reflected a new era of American art that continues to this day, is a crucial task.

\section{Materials and Methods}

The features of American modern dance were studied through analysis of theoretical, historical scientific material, generalisation of information from primary sources (statements of artists on the topic covered), visual and textual analysis of choreographic performances and music for performances from the point of view of organising a work of art, comparison of means of plastic expression, movements and figures of classical ballet and modern dance, principles of stage development of artistic images of performances. The empirical study is based on the generalisation of the practical experience in staging performances by leading American choreographers and the performing activities of dancers of the 20th century. The subject matter of the study was the work of M. Cunningham (1919-2009) a leading figure in modern dance, who developed the theoretical foundations and practical approaches to the creation and performance of modern dance.

Scholars have emphasised and thoroughly investigated such aspects of the US choreographic art as the role of Russian dancers and choreographers in the development of American culture (Horowits, 2008), the development of Russian ballet traditions by emigrants (Vedernikova, 2012), the development of national traits and major innovators' search for their ballet style (Snow, 2019; Kudryavtseva, 2012), the Americanisation of neoclassical ballet in the work of Balanchine (Harris, 2017), the technical features of individual dance schools and styles (Jones, 2002; Omelnitskaya, 2015), the semiotic system of classical ballet performance, including "dancing body as a sign within a network of semiotic chains, such as the inter-semiotic regulation of the body of the dancer by principles coming from painting" (Atã \& Queiroz, 2019), psychology and technology of classical ballet (Schantz \% Åstrand, 1984), the problem of syncretism of ballet genres, including modern dance style (Kudryavtseva, 2010), specifics of dance improvisation (Matushkina, 2014), innovative plastic elements in modern dance (Sadovnikova, 2012), stage 
design of contemporary dance (Portnova, 2019a), innovations in teaching art (Gavran et al., 2021; Portnova, 2019b), etc.

The specificity of American modern dance has rarely been researched. There is a study dedicated to the choreographic aleatory in the work of M. Cunningham and the principles of composition in his performances (Pereverzeva, 2018b). M. Cunningham is an avant-garde American innovative choreographer, whose style has developed under the influence of Dadaism, abstractionism, surrealism and other movements in contemporary art. M. Cunningham's involvement in the world avant-garde pushed him to search for an alternative to the classical ballet style of choreographic art, which could reflect the features of the national American culture. According to M. Pereverzeva (2018a), "M. Cunningham's modern dance and choreographic aleatory developed on both sides of the Atlantic". Until his elderly years, M. Cunningham was a teacher, held master classes and lectures-demonstrations around the world, mainly in the United States and European countries (he was frequently invited to Paris in particular). His concepts of modern dance and choreographic aleatory still generate new creative ventures of avant-garde artists around the world.

The studies of American modern dance reveal that it is "a multi-genre and aesthetically diverse phenomenon", where "there is no strict order of movements, and the personal approach of contemporary dancer is of great importance" (Sadovnikova, 2012). M. Pereverzeva emphasises the expressiveness of gesture and movement in modern dance, improvisation, rejection of traditional ballet costume, appeal to avant-garde music and independence from the canons of classical ballet (Pereverzeva, 2018b). Other scholars emphasise the continuity of the development of dance improvisation, from the free dance of A. Duncan, the early modern dance of R. Saint Denis to postmodern dance, and the use of "pure", "natural" movements by American choreographers, which "should have been born from the creativity of a particular person that brings out such features of modernity as accidental, transitional, fleeting" (Matushkina, 2014). T.A. Kudryavtseva (2010) notes that "each era creates its model of dance thinking. The choreographic language forms dance consciousness in a given social environment but it is inextricably linked with the historical processes of the development of various types of art in addition to the communication through dance". Thus, certain aspects of American classical ballet and modern dance have been investigated, but the cultural and historical reasons for the development of modern dance in the United States have not been identified, the artistic and aesthetic principles of both choreographic styles, and a connection between modern dance and the latest trends in American art of the early 20th century were not compared and analysed.

\section{Results and Discussion}

The study revealed that the artistic and aesthetic, and compositional and technical principles of modern dance are completely different to those of classical ballet of the United States. They helped Americans to highlight the problems of the time, reflect the features and national traditions of a unique multicultural society, convey the spirit of avant-garde and actively developing mass culture at the same time The emergence of modern dance was preceded by significant discoveries in philosophy, science and art. Visual, musical and choreographic art and literature has undergone dramatic changes influenced by science and philosophy of the late 19th 
and early 20th centuries (relativistic concepts, quantum mechanics, Heisenberg's uncertainty principle, Einstein's law of relativity, etc.), which refuted traditional ideas about the world and opened up new sides of the universe (Popovych, 2019).

The scientifically proven uncertainty and relativity of the world and human cognition have debunked the idea of completeness and perfection of the creative act (Volkova et al., 2020). "Under these circumstances, the introduction of randomness into a work of art, the desire to bring it closer to complexity, variability, and the ever-present element of instability of natural processes become deeply immanent" (Valkova, 1977). In the 1950s, aleatory flourished in music (Pereverzeva, 2018a). However, aleatory or similar concepts appeared in architecture, painting, literature and choreography long before in music. In the first half of the 20th century, mobile, or open works, works-in-motion with an indefinite form and changing meaning appeared (Eco, 2004). The problem of a mobile or open work of art held a special place in aesthetics. The German philosopher T. Adorno studied the phenomenon of the "open form" associated with the semantic and structural uncertainty of a work of art in the 20th century, and coined the term. The Italian philosopher U. Eco (2004) proposed the concepts of "open work" and "work in movement". Both phenomena stem from the idea of refuting the traditional attitude to the completeness of the form that has developed in recent centuries.

U. Eco (2004) distinguishes between "open work" and "work in movement", defining the works that have a complete form but allow an infinite number of interpretations as "open". For example, the novel "Finnegans Wake" by J. Joyce is an "open work". A "work in movement" presupposes an initially unfinished form based on the factor of chance. For instance, in the "Book" by S. Mallarmé, the pages can be arranged and read in any order, so that randomness turns out to be not only a structural property that determines its mobility but also a consistently deployed plot. Here, the category of novelty, originality and artistic uniqueness of the opus is of particular importance, including the uniqueness of the form, which does not provide for a final and clearly fixed structural organisation and causes the effect of incompleteness. Thus, the role of the performer in the interpretation of the composition and the interpretation of its form becomes more prominent. One of the vivid examples of an open and mobile form are the choreographic performances of $\mathrm{M}$. Cunningham that reflect a new vision of the world immanent to the avantgarde artists of the 20th century.

The stylistic features of classical ballet are the plot organisation of the dance based on showing successively change of episodes from myths, fairy tales, historical events, literary works; a libretto for a musical and stage performance; the use of historically established musical and choreographic forms: solo, duet, group (mass dances); belonging to a certain type (narrative, drama ballet, plotless ballet-symphony or miniature) and genre (comic, heroic, folklore); meticulous development of various groups of movements and positions of the legs, arms, body and head; striving for geometric clarity of movements, following the principle of eversion (Dimura \& Makarova, 2016). The main types of dances in ballet are classical dance and character dance. Pantomime plays an important role here, allowing the actors to convey the feelings of the characters, their "conversation", the essence of what is happening, harmony of music and dance, which are inextricably connected. At the same time, according to A. LaViers and M. Egerstedt (2011), "language in classical ballet, i.e., sequences of movements, make up canonical warm-up routines". 
The founders of modern dance R. Saint-Denis and T. Shawn hid these features on purpose, and later choreographers and dancers avoided them altogether. Notably, at the ballet school R. Saint-Denis and T. Shawn philosophy and related arts were studied along with dancing. The pioneers of modern ballet used new groups of movements and positions, introduced elements of gymnastics and acrobatics. Modern dance directors avoided inverted legs, traditional positions of arms, body and head, high jumps, principles of verticality of the body and isolation of its various parts, as well as geometric clarity of movements. It all began with the emergence of new, sometimes unexpected elements of the dance and a radical metamorphosis of the dancers' appearance. The renowned choreographers of the USA felt the conventionality, stereotype, exhaustiveness of plots, images and means of expression of classical ballet, the lack of opportunities to demonstrate their skills, fresh ideas and modern images. Viewing American ballet within a framework of literary, musical, art, and dance modernism, A. Harris (2017) "examines a series of critical efforts, especially by Lincoln Kirstein and Edwin Denby, to develop new, modernist ideas about the relevance of classical dancing for American society". Modern dance abandoned tutus and pointe shoes in favour of loose, light, elongated ballet dancers' robes that create an airy, sophisticated image. Many dancers performed barefoot on stage. Modern ballet takes into account the natural plasticity of the body, which allows performing complex movements and modern trends in choreography, which gives freedom of variations and combinations, highlighting special expressiveness of the dance (Kvetsko, 2020).

Modern dance reached its peak development in the work of the most prominent US artist M. Cunningham, who worked over 70 years and influenced the image of nowadays American choreographic art. M. Cunningham's productions encapsulate the most important stylistic features of modern dance since he was sensitive to the latest trends in contemporary art and, at the same time, possessed American thinking, was a "patriot" of the national American culture. During the period of experiments in the field of American "painting of action," the innovative choreographer M. Cunningham developed a choreographic aleatory that contributed to a mobile form of dance performance in creative collaboration with avant-garde composer J. Cage, which lasted for many decades (Pereverzeva, 2018b). He studied at the Cornwall School of Fine Arts, Mills College, then performed as a soloist in the M. Graham choreographic troupe. Later, he created his troupe (1942) and the Dance Company of his name (1952), which still exists. J. Cage worked as Music Director of the M. Cunningham Dance Company from 1944 to 1966, he wrote music for most of M. Cunningham's performances, and together they created a new look of American modern dance.

M. Cunningham also staged choreographic performances to the music of L. Moreau Gotchok, E. Satie, I. Stravinsky, A. Hovaness, L. Harrison, P. Boulez, K. Wolfe, E. Brown, M. Feldman, G. Mamma, D. Berman, B. Nilson, B. Johnston, K. Nankarrow, T. Ichiyanagi, L.M. Young, P. Oliveros, A. Luciera, M. Monk, T. Kosugi, L. Austin, R. Ashley, P. Schaeffer and P. Henri. This is not just an impressive list of names of musicians. They all belong to the largest composers of the 19th and 20th centuries. Using material from the "Symphony for One Person" (this is a sample of the socalled "concrete music", which is sound recording of environmental noises), M. Cunningham created a choreographic composition of the same name and presented it to the audience in 1952. This was the first performance of concrete music in the USA. The scenery for the performances of M. Cunningham was created by the leading surrealist artists M. Ernst and his wife P. Guggenheim, 
abstractionists J. Jones, W. de Kunning, R. Rauschenberg and many others. The choreographer worked closely with the avant-garde poets and writers of the United States. Thus, M. Cunningham combined in his work the latest trends of the 20th century US art and reflected the spiritual aspirations of his contemporaries.

The dancer was defined by the desire to move away from the unidirectional logical sequence of the presentation of thought and the development of the image in a work of art towards improvisation, as well as the idea of "randomness" as a way of creating an artistic unity. He introduced unusual, as well as free body movements and gestures of a person as choreographic elements. He was engaged in the expansion of the traditional repertoire of modern dance. He allowed an element of randomness in stage compositions. The random connections of daily sounds, facts, events became the model for new movements. M. Cunningham "uses randomness at all levels of dance creation, defining vocabulary, composition, and relationships with other authors, particularly musicians and artists" (Surits, 2004). The innovative principles of the master of modern dance were based on his desire to introduce the possibility of performing different movements at the same time, so that all dancers were soloists, every their actions reflected an artistic meaning and presented a different view of what was happening; use free movements of dancers and their random combinations to achieve the effect of unpredictability, enhancing the expressiveness and semantic depth of the choreographic performance; finally, to create a multidimensional stage space, where each point is equal to all others and shows one of the many facets of the artistic image. "When I accidentally read the famous statement by $A$. Einstein about "no fixed (constant, unchanging) points in space", I thought, if there are no fixed points, then each point is equally interesting and equally replaceable" (Cunningham \& Lesschaeve, 1991). Randomness opens up endless expressive and compositional possibilities for choreography: "Since you are not associated with a particular sequence, you can always change anything, the movement can be continuous, and the number of transformations can be unimaginable" (Cunningham \& Lesschaeve, 1991).

M. Cunningham associated dance with water, and the composition with a fluid, changing, mobile, unstable element. In another conversation, he said that he "considers dance to be a permanent transformation of life itself" (Cunningham \& Lesschaeve, 1991). Hence there is multidimensional, multilinear, flexible and mobile drama of a choreographic performance. In addition, the artist "never thought and still does not think that dance is something intellectual", rather it is "something instinctive" (Cunningham \& Lesschaeve, 1991). Dance for him ceased to be a static space where all actions are connected with each other. His dancers performed different movements in different rhythms, easily joined to what was happening, added any artistic element to the composition, created different groups of soloists and changed the composition ensembles throughout the composition, which made it possible to show a multifaceted image from several angles, consider the problem from different perspectives and add new semantic touches to what is happening on the stage. M. Cunningham strove to ensure that each dance was individualised. Therefore, he built choreographic performances using the "I Ching" method of random actions and many plans, drawings and tables for selecting and combining elements of the future work. For example, for the dance "Untitled Solo" (1953), the choreographer first prepared a set of movements for the arms, legs, torso, and head by writing them all down; then, set their order and combinations by tossing up the dice; finally, he randomly combined and developed dance 
phrases. According to M. Cunningham, the experience of working with randomness showed him that "you can go from one movement to another, arising spontaneously without my participation, that you can create your coordination of movements and that, probably, the human body can do what before was considered impossible" (Surits, 2004). The use of dice revealed to him that "everything that we thought was unattainable was possible, and it became obvious that we could do it if we only thought in this way (use the mind in this way; would perceive such a way of thinking)" (Cunningham \& Lesschaeve, 1991).

Another method of applying the factor of randomness is M. Cunningham's determination of all movements for each part of the body and writing them all down on sheets of paper. Then he pulled out the sheets until he had a full set of movements for the head, arms, body, legs, etc. In addition, the choreographer offered each dancer a large number of different gestures, which they could choose at will and show in any order as in the third part of the play "Used" (1970). These gestures "could be retained or changed by the dancer in combination with the other movements he performed" (Cunningham \& Lesschaeve, 1991). Such spontaneous organisation of a choreographic work and changes that are barely noticeable in the play were compared by $\mathrm{M}$. Cunningham to the leaves of trees: "If you look at a tree, you will not find two similar leaves, even if they have the same shape and structure" (Cunningham and Lesschaeve, 1991). In the process of working on the "Garland" dance (1976), M. Cunningham prepared beforehand individual phrases consisting of movements from one to sixty-four (according to the number of hexagrams of the "Book of Changes") and a scene diagram, breaking it into sixty-four squares (8x8) and then, he determined the numbers and combinations of phrases, the number and location of dancers on the stage by using random actions. The dance was formed by itself, symbolising the continuous change inherent in nature. Experiments with a large number of figures were determined not only by artistic but also by purely practical tasks such as M. Cunningham's desire to develop all possible movements of the fingers and hands. But the main idea is that the director needed the uniqueness of each dance phrase that arises in a random combination of movements.

Through his creative path, the choreographer abandoned the traditional type of figurative and emotional expressiveness in favour of fundamentally new content of the choreographic performance. M. Cunningham and J. Cage avoided the "literary" and "descriptive" in a work of art, which should not have any plot, should not narrate about anything and not express anything specific. The content of music should be music, of dance-dance, of painting-painting. All the other features of the work of the leading American cultural figures of the middle and second half of the 20th century derive from this fundamental idea. For M. Cunningham and many dancers who followed him, "anything could be a dance" (Surits, 2004). Thus, what is happening on the stage should not be associated with a specific plot, i.e., an order of specific events, to focus the audience's attention on the dance itself. Hence, there are "incoherence" of unexpected combinations of movements, "plotlessness" of performances, when "events take place for no apparent reason" and "what derives from them is insignificant" (Surits, 2004).

Randomness opened not just the path to freedom for M. Cunningham, which allowed him to discover previously unused choreographic possibilities and expand the range of movements used in dance, but most importantly it allowed for the unexpected discoveries in relation to the movements themselves and their sequences, the most unexpected results and previously unseen combinations. The dance performance takes on an unusual form and unexpected character due 
to the "mismatched" combination of body positions, new movements and an unconventional perspective at high speed. According to M. Cunningham, randomness reveals to him a world beyond imagination. At the same time, the very essence of space and time changes, the form of the dance becomes mobile, and when all the participants are constantly in motion, disappearing and appearing in the most unexpected places, the stage seems to be limitless since all its sections are equally important and all dancers and their directions of movement are equal in their meaning.

However, randomness did not have an absolute value for $M$. Cunningham's performances. As the philosopher N. Goodman noted, "even the canvases of the abstractionists over time lead the eye to a certain geometric regularity, circular shapes, arabesques, black and white contrasts, colour consonances and dissonances" (Antiseri \& Reale, 1997). In his productions, M. Cunningham used the method of periodically connecting all dancers to a unison group, which plays the role of a stabilising factor in the composition, and the subsequent disintegration of these groups, when the performers continue to move in different directions, rhythms and dynamics, and then reunite. The choreographer also used the method of rhythmic organisation of time based on a number series with repeating groups of numbers. The unifying compositional function in his productions was also performed by a certain type of movement, which periodically returned throughout the entire performance.

M. Cunningham practiced a random combination of different types of art in a creative union with many like-minded people (D. Tudor, D. Berman, K. Wolfe, La Monte Young, R. Rauschenberg, J. Jones). The artists strove for complete independence of the dance from music and vice versa that takes place on the stage from the scenery. The randomness of the combinations allowed for preserving fully their logic of development and expressiveness of each form of art, to maximise the attention and creative participation of the audience, to stimulate their imagination. The composer, choreographer and painter agreed only on the duration of the action, the size of the stage, and the general nature of the performance. "It was not a fusion of the component parts into one entity, into one performance - not at all. It was a collage where elements coexist without connecting. The audience wants us to perceive us on three different levels at the same time, to create three different forms, and to feel those light moments of interaction. The result is very complex and requires conscious spectator participation, but it is also full of surprises like no other theatrical experience" (Surits, 2004).

Scientific discoveries and artistic innovations in different types of art have stimulated changes in artistic and aesthetic principles, genre and style palette and compositional and technical arsenal of different types of art (Poplavskyi, 2019). Original ideas, means of expression and new methods of composition, radically different from those that were guided by artists of previous eras, determined the development of American art of several generations, beginning in the 1940s. Due to the development of distinctive national American culture new styles and genres appeared in all types of art. Thus, the foundation of American modern dance was developed by artistic-aesthetic and compositional-technical principles, completely different to classical ballet: natural human body movements, unusual and free gestures, elements of sports movements instead of classical "pas" and their combinations; free composition of movements outside a specific plot instead of a clear order of events that form a certain plot with the logical development of images; independence of the artistic components of a dance performance (music, movements, scenery, costumes) instead of mutual conditioning and connection. Random combinations of 
movements and figures and their random order of M. Cunningham's dance composition are not at all devoid of emotional impact on the audience and figurative and semantic content. However, they require active perception and involvement in what is happening. Abstract artistic images of choreographic performances, in the absence of plot and consistent eventfulness, generate multiple associative connections, allusions and analogies with other types of art, styles, genres, eras.

\section{Conclusions}

To conclude, at the end of the 19th and beginning of the 20th century, when purely American phenomena with their unique artistic originality became widespread, the orientation towards European art ceased to be unconditional. National styles and genres of art have long remained unnoticed by the people of the United States of America. For example, American musicians recognised the value of distinctive national types of folk music later than Europeans. Among them were cowboy songs, spirituals, blues, country music. But in the beginning of the 20th century, a period of development of national artistic traditions began in American culture. The first half of the 20th century was full of the active research activities of famous American folklorists. Almost all major US artists of the first half of the 20th century studied the art of various ethnic groups in the US.

The internationality of American culture has given rise to the diversity of styles, schools, and movements that define 20th century US art. American dancers were looking for new ways of developing classical ballet, and many of them preferred the principles of the new, avant-garde art of the USA, which undoubtedly made a significant contribution to the global heritage, to the artistic and aesthetic principles of European choreographic art. The influence on world art of the greatest choreographer and modern dancer M. Cunningham, who integrated the leading artistic trends of the era in his work, is so strong that his ideas were further developed in the global culture of the 21st century. Modern dance has served as the foundation for many contemporary styles in both academic and pop art. American dancers were first to "dare" to use non-classical movements and their out-of-plot combination and order on the professional stage. In modern choreography, modern dance holds an important place among the leading styles of plastic art since it reflected the latest trends in the art of the 20th century.

\section{References}

Antiseri, D. \& Reale, G. (1997). Western philosophy from the beginnings to the present day: from romanticism to the present day. Saint Petersburg: Petropolis.

Atã, P. \& Queiroz, J. (2019). Emergent sign-action classical ballet as a self-organised and temporally distributed semiotic process. European Journal of Pragmatism and American Philosophy, 11(2), 119.

Cunningham, M. \& Lesschaeve, J. (1991). The dancer and the dance. Merce Cunningham in conversation with Jacqueline Lesschaeve. London: Marion Boyars Publishers. 
Dimura, I.N. \& Makarova, D.S. (2016). Dance expressiveness of ballet dancers: on the question of definitions. Bulletin of the Academy of Russian Ballet. A. Ya. Vaganova, 4(45), 20-30.

Eco, U. (2004). Open work. Form and uncertainty in contemporary poetics. Saint Petersburg: Akademicheskiy proyekt.

Gavran, I.A., Hutsal, R.S., \& Tsaruk, S.M. (2021). Motivation as a core aspect of the development of professional skills and abilities in the period of distance learning of art students. Scientific Bulletin of Mukachevo State University. Series "Pedagogy and Psychology", 7(3), 94-101.

Harris, A. (2017). Making ballet American: Modernism before and beyond balanchine. Oxford: Oxford University Press.

Horowits, J. (2008). Artists in exile: How refugees from 20th-century war and revolution transformed the american performing arts. New York: HarperCollins.

Jones, B. (2002). Voices of the body. In: J. Dunbar (Ed.), Jose Limon: An artist re-viewed (37-43). London: Routledge.

Kiseyeva, E.V. (2017). Musical and choreographic performance as the topical form of the musical theater. South-Russian Musical Anthology, 4, 90-95.

Kudryavtseva, T.A. (2010). Combining ballet genres of the early 20th century: academism and innovation (problem statement). Bulletin of the Academy of Russian Ballet. A. Ya. Vaganova, 2(24), 178-188.

Kudryavtseva, T.A. (2012). Jose Limón and his role in the pioneering quest for contemporary theater. Bulletin of the Academy of Russian Ballet. A. Ya. Vaganova, 28(2), 316-324.

Kvetsko, O.Ya. (2020). Pedagogical fundamentals of methods of teaching choreographic disciplines. Scientific Bulletin of Mukachevo State University. Series "Pedagogy and Psychology", 6(2), 145152.

LaViers, A. \& Egerstedt, M. (2011). The ballet automaton: A formal model for human motion. In: Proceedings of the American Control Conference (3837-3842). Piscataway: IEEE.

Matushkina, M.V. (2014). Dance improvisation: origins and history of development at the beginning of the 20th century. Theory and Practice of Social Development, 9, 98-101.

Mykulina, A.K. (2018). Development of aesthetic culture of future teachers by means of fine arts. Bulletin of Mukachevo State University. Series "Pedagogy and Psychology", 1(7), 115-118.

Omelnitskaya, V.V. (2015). Features of the performing technique in ballets by G. Balanchine. Bulletin of the Academy of Russian Ballet. A. Ya. Vaganova, 1(36), 48-50.

Pereverzeva, M., Anufrieva, N., Shcherbakova, A. \& Anufriev, E. (2018). USA music as a reflection of the national sociocultural values. In: Proceedings of the 34th International Scientific Conference on Economic and Social Development (840-846). Varazdin: Varazdin Development and Entrepreneurship Agency.

Pereverzeva, M.V. (2018a). Aleatorics as a principle of composition. Saint Petersburg: Planeta muzyki.

Pereverzeva, M.V. (2018b). Choreographic aleatorics by M. Cunningham in the context of mobile works of art. Bulletin of the Academy of Russian Ballet. A. Ya. Vaganova, 4(57), 71-90.

Poplavskyi, M. (2019). Entrepreneurship in the field of art business in the European union. Journal of Entrepreneurship Education, 22(6), 6 pages. 
Poplavskyi, M., Rybinska, Y. \& Ponochovna-Rysak, T. (2020). The specific of Synesthesia in contemporary American and English poetry and its impact on the reader. Cogito, 12(3), 297-315.

Popovych, N.M. (2019). Scientific approaches towards formation professional and personal experience of a specialist of music art. Bulletin of Mukachevo State University. Series "Pedagogy and Psychology", 1(9), 100-103.

Portnova, T.V. (2019a). Costume and stage design dance. Moscow: Pero.

Portnova, T.V. (2019b). Traditions and innovations in the pedagogy of theatrical art on the example of foreign countries. Moscow: Nauchnyye tekhnologii.

Sadovnikova, L.A. (2012). The use of jazz dance and modern dance as innovative methods of plastic education in a creative university. Proceedings of the Saint Petersburg State Institute of Culture, 194, 157-165.

Schantz, P.G. \& Åstrand, P.-O. (1984). Physiological characteristics of classical ballet. Medicine and Science in Sports and Exercise, 16(5), 472-476.

Snow, K.M. (2019). Orientalised aztecs: Observations on the americanisation of theatrical dance. Dance Research Journal, 51(2), 35-50.

Surits, E. (2004). Ballet and dance in America: essays on history. Yekaterinburg: Ural University Publishing House.

Valkova, V. (1977). Aleatoric Lutoslawski and the peculiarities of its use in the Second Symphony. In: V.M. Tsendrovskiy, B.S. Getselev, G.L. Danileyko, O.V. Sokolov (Eds.), Problems of 20th century music (pp. 272-291). Gorky: Volgo-Vyatskoye book publishing house.

Vedernikova, M.A. (2012). Relaying of achievements of Russian school of classical dance in activity of ballet emigrants of the first wave, 1917-1939. Yaroslavl Pedagogical Bulletin, 1(1), 282-284.

Volkova, P.S., Orekhova, E.S., Saenko, N.R., Trofimova, L.V. \& Barova, A.G. (2020). Features of the modern process of differentiation of sense and meaning in communication. Media Watch, 11(4), 679-689. DOI: $10.15655 / \mathrm{mw} / 2020 / \mathrm{v} 11 \mathrm{i} 4 / 204639$ 